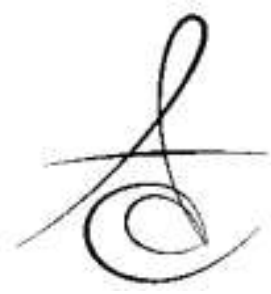

\section{BEŞ FARKLI AKICI KOMPOZİT REZİNİN RADYOOPASİTELERİNİN KARŞILAŞTIRILMASI ${ }^{*}$}

\section{COMPARATIVE RADIOPACITIES OF FIVE FLOWABLE RESIN COMPOSITES ${ }^{\ddagger}$}

\author{
Dt. Kübra CANTÜRK* \\ Dt. Furkan CANTÜRK**
}

Prof. Dr. Nilgün SEVEN*
Kübra Cantürk: ORCID ID: 0000-0002-1140-2262

Merve Nur Yılmaz: ORCID ID: 0000-0002-8037-6408

Furkan Cantürk: ORCID ID: 0000-0002-7968-6855

Nurcan Özakar İlday: ORCID ID: 0000-0003-4023-6723

Nilgün Seven: ORCID ID: 0000-0003-0690-2200

öz

Amaç: Restorasyonlarda kullanılan dental materyallerin radyoopasiteleri, radyografik tanıların konulmasında oldukça önemlidir. $\mathrm{Bu}$ sebeple çalışmamızda farklı akıcı kompozit rezinlerin dijital bir görüntü analizi kullanılarak radyoopasitelerinin değerlendirilmesi amaçlanmıştır.

Yöntem: 5 farklı akıI kompozit rezin [ (Aeliteflo, BISCO), (Brillant Ever Glow, Coltène), (Dynamic Flow, President Dental), (Gænial Universal Flo, GC Corp.), (Novo compo-HF, Imicryl)] her grup için üç adet disk şeklinde $1 \mathrm{~mm}$ kalınlığında $8 \mathrm{~mm}$ çapında örnek teflon kalıplar kullanılarak hazırlanmıştır. Kontrol grubu için yeni çekilmiş dişten mine ve dentini içerecek şekilde $1 \mathrm{~mm}$ kalınlığında kesit alınmıștır. Örnekler alüminyum step-kama ile birlikte okluzal film üzerine yerleștirilmiş ve $60 \mathrm{kV}, 7 \mathrm{~mA}$ ve $0.13 \mathrm{sn}$ değerlerinde dijital radyograf alınmıştır. VistaScan cihazıyla dijital ortama aktarıldıktan sonra alüminyum step-kamanın ve akıCı kompozit rezinlerin radyoopasiteleri Adobe Photoshop CS5 programıyla 10x10 piksellik farklı alanlardan hesaplamalarla ortalama grilik değerlerine (MGVs) çevrilmiştir. Akıcı kompozit rezinler için eşdeğer alüminyum kalınlığı CurveExpert Professional programı ile hesaplanmıştır.

Bulgular: Kullanılan akıc kompozit rezinlerin Al eşdeğer radyoopasitelerinin sıralaması; Novo compo-HF $(2,81 \mathrm{~mm}$ Al) $>$ Brillant ever glow $(2,15 \mathrm{~mm} \mathrm{Al})>$ Aeliteflo $(1,64 \mathrm{~mm} \mathrm{Al})>$ Dynamic flow $(1,61 \mathrm{~mm} \mathrm{Al})>\mathrm{G}$-ænial Universal Flo $(1,19 \mathrm{~mm} \mathrm{Al})(p<0,05)$ şeklindedir. G-ænial Universal Flo ve dentin $1 \mathrm{~mm}$ Alüminyum radyoopasite değerine istatistiksel olarak en yakın sonucu vermiştir. Novo compo-HF mineden daha radyoopak olmakla beraber yakın MGV' ye sahiptir.

Sonuç: Akıcı kompozit rezinlerin radyoopasiteleri önemli ölçüde çeşitlilik göstermektedir. Akıcı kompozit rezinlerin, uygulanan kompozit rezin restorasyonların altında sekonder çürükle karıştııımaması ve farklı materyal kullanıldığının belirlenebilmesi için farklı radyoopasite değerlerinde seçimler yapılabilir. Ayrıca radyografik analiz yapılırken bu farklı radyoopasite değerlerinin bilinmesi diagnostik değerlendirmede ve teşhiste yardımcı olacaktır.

Anahtar Kelimeler: Akıcı kompozit rezin, radyoopasite, ortalama grilik değeri

\title{
ABSTRACT
}

Aim: The radiopacities of the dental materials in the restoration are very important in getting radiographic diagnosis. For this reason, we aimed to evaluate the radiopacity of different flowable composites using a digital image analysis.

Methods: For the 5 different flowable resin composites [(Aeliteflo, BISCO), (Brillant Ever Glow, Coltène), (Dynamic Flow, President Dental), ( G-ænial Universal Flo, GC Corp.), ( Novo compo-HF, Imicryl)]; 3 discs with a thickness of $1 \mathrm{~mm}$ and a diameter of $8 \mathrm{~mm}$ were prepared with using teflon mold. For the control group, a slice of $1 \mathrm{~mm}$ thickness was taken to contain enamel and dentin from the freshly extracted tooth. The samples were placed on an occlusal film with the aluminum step wedge and the film was exposed with a dental x-ray unit at $60 \mathrm{kV}, 7 \mathrm{~mA}$, and 0.13 second. After transferring to the digital image using VistaScan; the radiopacities of aluminum step-wedges and the flowable resin composites were converted to mean gray values (MGVs) from different areas which is $10 \times 10$ pixel by Adobe Photoshop CS5 program. Equivalent aluminum thickness for each flowable resin composite is calculated with the CurveExpert Professional Program.

Results: The order of the Al equivalent radiopacities of the flowable resin composites used is as follows; Novo compo-HF $(2,81 \mathrm{~mm} \mathrm{Al})>$ Brillant ever glow $(2,15 \mathrm{~mm} \mathrm{Al})>$ Aeliteflo $(1,64 \mathrm{~mm} \mathrm{Al})>$ Dynamic flow $(1,61 \mathrm{~mm} \mathrm{Al})>\mathrm{G}$-ænial Universal Flo $(1,19 \mathrm{~mm} \mathrm{Al})(p<0,05)$. G-ænial Universal Flo and dentin got the closest result to $1 \mathrm{~mm}$ Aluminum radiopacity value statistically. The Novo compo-HF is more radiopaque than the enamel and has close MGV.

Conclusion: The radiopacity of flowable resin composites varies considerably, Selections can be made at different radiopacity values so that they do not be confused with secondary caries under the applied composite restorations and indicate that different materials are used. In addition, knowing these different radiopaque values while performing radiographic analysis will help diagnose.

Keywords: Flowable resin composites, radiopacity, mean gray value

* Atatürk Üniversitesi, Diş Hekimliği Fakültesi, Restoratif Diş Tedavisi Anabilim Dalı, Erzurum

${ }^{* *}$ Atatürk Üniversitesi, Diş Hekimliği Fakültesi, Ağız, Diş ve Çene Radyolojisi Ana Bilim Dalı, Erzurum

${ }^{*}$ Bu çalışma Estetik Diş Hekimliği Akademisi Derneğinin (EDAD) 22. Uluslararası Bilimsel Kongresinde (19-21 Ekim 2019, İstanbul, Türkive) poster olarak sunulmustur

Kaynakça Bilgisi; Cantürk K, Yılmaz MN, Cantürk F, Özakar İlday N, Seven N. Beş Farklı Akıcı Kompozit Rezinin Radyoopasitelerinin Karșılaștırılması. Atatürk Üniv Diş Hek Fak Derg 2020; 30: 418-3.

Citation Information: Canturk $\mathrm{K}_{4}$ Y Yilmaz $\mathrm{MN}_{4}$ Canturk $\mathrm{F}_{1}$ Ozat Ilday N, Seven N. Comparative Radiopacities of Five Flowable Resin Compostes. J Dent Fac Atatürk Uni 2020; 30: 418-3. 


\section{GİRİŞ}

Akıcı kompozit rezinler, kompozit rezinlerin esas problemlerinden biri olan polimerizasyon büzülmesini azaltmak ve gelen streslere karşı stres kırıcı bir bariyer oluşturmak amacıyla restoratif diş hekimliği uygulamalarında sık kullanılan materyallerden biri olmuştur. ${ }^{1-3}$ Akıcı kompozit rezinlerin viskozitelerinin düşük olması sayesinde kavite duvarlarına adaptasyonları çok iyidir. $\mathrm{Bu}$ nedenle de akıc kompozit rezinlerin kavite liner olarak kullanımları önerilir. ${ }^{4,5}$ Akıcı kompozit rezinlerin klinik kullanımına başlanmasıyla mikrosızıntıyı engellemesi, restorasyon altında bariyer etkisi görmesi, düşük viskozitesi sayesinde adaptasyonunun iyi olması var olan mikro çatlakları kapatması gibi avantajlarıyla geleneksel kompozit rezin restorasyonlarda karşılaştığımız başarısızlıkların önüne geçilmeye çalışılmıştır. ${ }^{2}$

Restorasyonlarda kullanılan materyallerin radyoopasiteleri, özellikle posterior dişlerde restoratif materyal ile diş yüzeyleri arasındaki bölgelerin radyografik olarak daha iyi görüntülenmesi açısından önemlidir. ${ }^{6}$ Radyoopak restoratif materyaller başta sekonder çürük teşhisi olmak üzere marjinal defektler, hatalı proksimal konturlar ve restorasyonun pulpaya yakınlığı hakkında da bilgi verir. ${ }^{7,} 8$ Dental materyallerin radyoopasiteleri üzerindeki çalışmalar özellikle kaide materyalleri olarak kullanılan akıcı kompozit rezinler üzerine yoğunlaşmıştır. ${ }^{9}$ Üretici firmalar akıcı kompozit rezinler içerisine doldurucular veya radyoopak bileşenler ekleyerek radyoopasitelerinin arttırılmasını amaçlamışlardır. ${ }^{10}$

Radyografik açıdan ideal radyoopasite derecesi restorasyon materyalinin kullanım amacı ve türüne göre değişiklikler gösterebilmektedir. ${ }^{11}$ Restoratif materyallerinin radyoopasitelerinin değerlendirilmesi genellikle mine, dentin ve alüminyum ile karşılaştırılarak yapılmaktadır. ${ }^{12}$ Minenin aynı kalınlıktaki alüminyumun (Al) radyoopasitesinin yaklaşık iki katı radyoopasiteye sahip olduğu, dentinin ise yaklaşık olarak aynı kalınlıktaki alüminyumun (Al) radyoopasitesine eşdeğer olduğu belirtilmiştir. ${ }^{13}$

Literatürde akıcı kompozit rezinlerin radyoopasitesiyle ilgili sınırlı sayıda çalışma bulunmaktadır. Bu çalışmada beş farklı akıcı kompozit rezinin radyoopasitelerinin dijital bir görüntü analizi kullanılarak ortalama grilik değerlerinin mine ve dentinle kıyaslamalı olarak belirlenmesi amaçlanmıştır. Çalışmamızın sıfır hipotezi; çalışmada kullanılan akıcı kompozit rezinlerin radyoopasiteleri arasında herhangi fark yoktur olarak kurulmuştur.

\section{MATERYAL METOD}

\section{Örnek Hazırlanması}

Çalışmada kullanılan materyaller ve içerikleri Tablo $1^{\prime}$ de verilmiştir. Çalışmada 5 farklı akıcı kompozit rezin [ (Aeliteflo, BISCO, Inc. Schaumburg, IL / ABD), (Brillant Ever Glow, Coltène, Whaledent AG, Altstätten / İsviçre), (Dynamic Flow, President Dental GmbH, Münih / Almanya), ( G-ænial Universal Flo, GC Corp. ,Tokyo / Japonya), ( Novo compo-HF, Imicryl, Konya / Türkiye)] kullanılarak her grup için 3'er disk (1 $\mathrm{mm}$ kalınlık ve $8 \mathrm{~mm}$ çap) olacak şekilde örnekler hazırlandı. Örneklerin hazırlanmasında $1 \mathrm{~mm}$ cam üzerine selüloz asetat strip bant ve strip bandın üzerine de teflon kalıplar yerleştirilerek hazırlandı. Kompozit rezinler kalıplara yerleştirilip kondanse edildikten sonra selüloz asetat strip bant ve üzerlerine de $1 \mathrm{~mm}$ kalınlığında bir cam yerleştirildi. Hazırlanan örnekler LED ışık cihazı (Woodpecker LED-D, Guangxi, China) ile örneklerin üzerindeki cama temas edecek şekilde 20 sn. süre ile dik şekilde polimerize edildi. Makroskopik kusurlu örnekler (çatlaklar vb.) standartı sağlamak için çalışmadan çıkarıldı ve yerlerine yeni örnekler hazırlandı. Daha sonra örnekler $37 \pm 1^{\circ} C^{\prime}$ de distile suda 24 saat süreyle bekletildi. Kontrol grubu için ortodontik nedenlerle çekilmiş çürüksüz molar dişten mine ve dentin içeren $1 \mathrm{~mm}$ kalınlığında bir kesit alındı. 1 mm'lik mine / dentin numunesi, düşük hızlı bir Isomet kesit alma cihazı (Isomet Low Speed Saw 1000; Buehler, Lake Buff, IL, ABD) ile uzunlamasına kesit alınarak hazırlandı(Şekil 1).

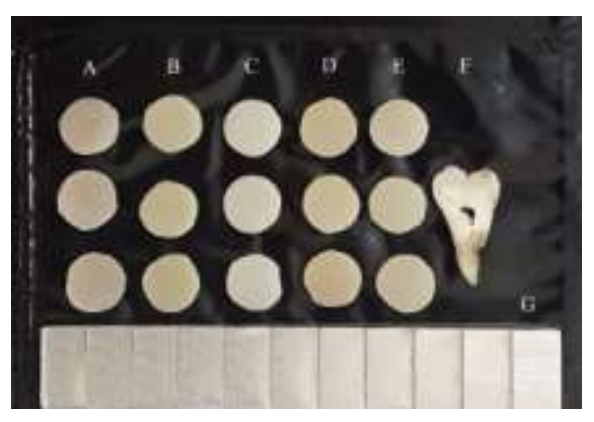

Şekil 1. Materyallerin oklüzal film üzerine yerleştirilmesi $[A]$ Aeliteflo B) Brillant ever glow C) Dynamic flow D) G-ænial Universal Flo E) Novo compo-HF F)Mine-Dentin Kesiti G) Alüminyum Stepwedge]

\section{Radyografik Prosedür}

$5.7 \times 7.6 \mathrm{~cm}$ 'lik bir ultra hızlı oklüzal film (Dürr Dental, Almanya) üzerine örnekler ve $1 \mathrm{~mm}$ basamak kalınlığında \% 99 saf alüminyum içeren kama yerleştirildi. Alüminyum basamağın amacı radyografik standardı sağlamak ve her malzemenin radyoopasi- 
tesine eşdeğer Al kalınlığını hesaplamaktır(Şekil 2). Film, 60kV, 7mA, 0.13 saniye ve $30 \mathrm{~cm}$ film-kon mesafesinde $X$-ray ışınına (Belmont Phot-X II, Osaka, Japonya) maruz bırakıldı. Tarayıcı olarak VistaScan kullanıldı.

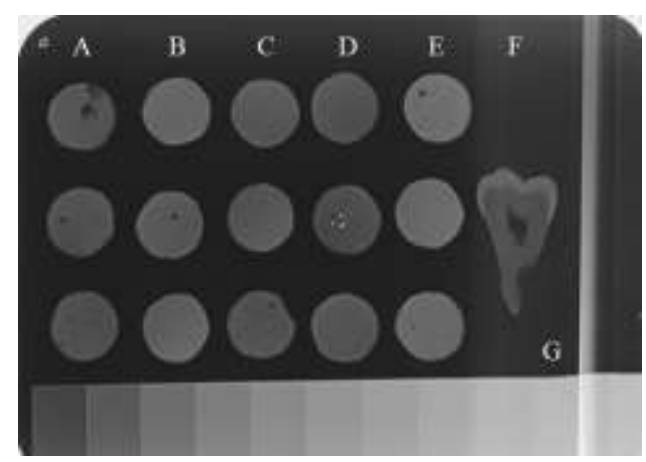

Şekil 2. Materyallerin Radyografik Görüntüsü $[A$ ) Aeliteflo B) Brillant ever glow C) Dynamic flow D) G-ænial Universal Flo E) Novo compo-HF F)Mine-Dentin Kesiti G) Alüminyum Stepwedge]

\section{Densitometrik Prosedür}

Alüminyum basamak kamalarının ve akıcı kompozit rezinlerin radyoopositelerinin her birinin ortalama grilik değerleri (MGV'ler), bir yazılım programı (Adobe Photoshop CS5, Adobe Systems, San Jose, CA, ABD) kullanılarak dijital radyografilerde ölçüldü. Her bir örnek için üç farklı bölgeden 10x10 piksel kadar radyoopaklık ölçümü yapıldı. Programdaki Yoğunluk Ölçme aracı ile 0-255 arasında MGV ölçüldü. Aynı prosedür, diş kesitinin mine, dentin ve pulpa üzerinde farklı bölgelerine de uygulandı. Her bir akıcı kompozit rezin için eşdeğer alüminyum kalınlığı CurveExpert Programı (Hyams D.G., Starkville, MS, ABD) kullanılarak hesaplandı. Ölçümler bir operatör tarafından yapıldı. Test edilen tüm malzemeler için radyoopasite değerleri, MGV'den milimetrelik alüminyum eşdeğerine (mm Al) dönüştürüldü. $\mathrm{Bu}$ amaçla, radyoopasite değeri, radyografinin üzerindeki alüminyum ölçeğinin (alüminyum basamak-kama) her basamağında da ayrıca ölçüldü. Ölçekteki her basamağın kalınlığına karşı radyoopasiteye ilişkin bir grafik oluşturuldu.

\section{İstatistiksel Analiz}

Elde edilen veriler değerlendirilirken, istatistiksel analizler için SPSS 20 (SPSS Inc; Chicago, IL, USA) programı kullanıldı. Kaydedilen değerler tek yönlü varyans analizi (ANOVA) kullanılarak analiz edildi ve farkın kaynağının belirlenmesinde Tukey Post-hoc analizi kullanıldı. (Güven aralığı \%95, p <0.05)

\section{BULGULAR}

Kullanılan akıcı kompozit rezinlerin MGV'leri ve Al 'e eşdeğer radyoopasite değerleri Tablo 2'de verilmiştir.

Kullanılan akıcı kompozit rezinlerin Al eşdeğer radyoopasitelerinin sırası $\mathrm{NHF}(2,81 \mathrm{~mm} \mathrm{Al})>\mathrm{BEG}$ $(2,15 \mathrm{~mm} \mathrm{Al})>\operatorname{AF}(1,64 \mathrm{~mm} \mathrm{Al})>\operatorname{DF}(1,61 \mathrm{~mm} \mathrm{Al})$ $>\operatorname{GUF}(1,19 \mathrm{~mm} \mathrm{Al})$ şeklindedir $(p<0,05)$. GUF $1 \mathrm{~mm}$ Al'a eşdeğer radyoopasite değeri gösterdi. Bu değer dentine en yakın radyoopasite değeridir. NHF, mineden daha radyoopaktır ve mineye yakın MGV'ye sahiptir. NHF' nin radyoopasitesi mineden yüksektir, yaklaşık olarak $2 \mathrm{~mm} \mathrm{Al}$ e eşdeğer radyoopasite değeri gösterir. NHF, BEG akıcı kompozit rezinlerin ve minenin radyoopasite değerleri istatistiksel olarak benzerdir. DF, AF ve dentinin radyoopasite değerleri istatistiksel olarak benzer değerler gösterdi $(p<0,05)$.

Tablo 1. Çalışmada kullanılan materyallerin üretici firma ve içerikleri

\begin{tabular}{|c|c|c|c|}
\hline Materyal & Üretici & Lot No & İçerik \\
\hline $\begin{array}{l}\text { Aeliteflo } \\
\text { (AF) }\end{array}$ & $\begin{array}{l}\text { BISCO, Inc. } \\
\text { Schaumburg, } \\
\text { Illinois / ABD }\end{array}$ & 1700000740 & $\begin{array}{c}\text { Etoksile Bisfenol A, } \\
\text { dimetakrilat, cam } \\
\text { partikülleri, } \\
\text { trietilenglikol, } \\
\text { dimetakrilat }\end{array}$ \\
\hline $\begin{array}{l}\text { Brillant } \\
\text { Ever } \\
\text { Glow } \\
\text { (BEG) }\end{array}$ & $\begin{array}{c}\text { Coltène, } \\
\text { Whaledent } \\
\text { AG, } \\
\text { Altstätten / } \\
\text { İsviçre }\end{array}$ & H78340 & $\begin{array}{l}\text { TEGDMA, BISGMA, } \\
\text { Çinko oksit kaplama }\end{array}$ \\
\hline $\begin{array}{l}\text { Dynamic } \\
\text { Flow } \\
\text { (DF) }\end{array}$ & $\begin{array}{l}\text { President } \\
\text { Dental } \\
\text { GmbH, } \\
\text { Münih / } \\
\text { Almanya }\end{array}$ & NXF1511242 & $\begin{array}{c}\text { Bisfenol A } \\
\text { dimetakrilat, üretan } \\
\text { dimetakrilat, } \\
\text { etoksilat bisfenol A, } \\
\text { dimetakrilat, } \\
\text { trietilenglikol } \\
\text { dimetakrilat, } \\
\text { trimetiltrimetakrilat, } \\
\text { gliserol dimetakrilat, } \\
\text { baryum alüminyum } \\
\text { boro silikat } \\
\end{array}$ \\
\hline $\begin{array}{l}\text { G-ænial } \\
\text { Universal } \\
\text { Flo (GUF) }\end{array}$ & $\begin{array}{l}\text { GC Corp. } \\
\text {,Tokyo / } \\
\text { Japonya }\end{array}$ & 1709073 & $\begin{array}{c}\text { Stronsiyum cam, } \\
\text { üretan dimetakrilat, } \\
\text { Bis-MEPP, } \\
\text { trietilenglikol } \\
\text { dimetakrilat, silikon } \\
\text { dioksit, pigment, } \\
\text { polimerizasyon } \\
\text { başlatıcı } \\
\end{array}$ \\
\hline $\begin{array}{c}\text { Novo } \\
\text { compo- } \\
\text { HF (NHF) }\end{array}$ & $\begin{array}{l}\text { Imicryl, } \\
\text { Konya / } \\
\text { Türkiye }\end{array}$ & 18073 & $\begin{array}{c}\text { Dimetakrilatlar, Bis- } \\
\text { GMA, Bis-MEP, } \\
\text { TEGDMA, UDMA, } \\
\text { silanlı baryum cam, } \\
\text { silanlı St-cam, } \\
\text { itterbiyum triflorür, } \\
\text { nano silikon dioksit, } \\
\text { silika-zirkonya } \\
\text { kompozit dolgu ve } \\
\text { prepolimer }\end{array}$ \\
\hline
\end{tabular}


Tablo 2. Ortalama Grilik Değerleri (MGV) ve Al ' e eşdeğer radyoopasite değerleri

\begin{tabular}{|l|l|l|}
\hline Kullanılan materyaller & $\begin{array}{l}\text { Ortalama Grilik } \\
\text { Değeri }\end{array}$ & $\begin{array}{l}\text { Radyoopasite } \\
\text { Değeri }^{*}\end{array}$ \\
\hline Aeliteflo & $85,33( \pm 2,3)^{\mathrm{de}}$ & $1,64( \pm 0,24)^{\mathrm{C}}$ \\
\hline Brillant Ever Glow & $95,33( \pm 3,1)^{\mathrm{bC}}$ & $2,15( \pm 0,11)^{\mathrm{B}}$ \\
\hline Dynamic flow & $86,66( \pm 2,3)^{\mathrm{Cd}}$ & $1,61( \pm 0,13)^{\mathrm{CD}}$ \\
\hline G-ænial Universal Flo & $77,33( \pm 2,6)^{\mathrm{ef}}$ & $1,19( \pm 0,08)^{\mathrm{D}}$ \\
\hline Novo Compo-HF & $107( \pm 2,8)^{\mathrm{a}}$ & $2,81( \pm 0,17)^{\mathrm{A}}$ \\
\hline Mine & $102,66( \pm 2,2)^{\mathrm{ab}}$ & $2,57( \pm 0,17)^{\mathrm{AB}}$ \\
\hline Dentin & $74,66( \pm 1,2)^{\mathrm{f}}$ & $1,34( \pm 0,14)^{\mathrm{CD}}$ \\
\hline Pulpa & $43( \pm 0,5)^{\mathrm{g}}$ & $0,59( \pm 0,08)^{\mathrm{E}}$ \\
\hline $\begin{array}{l}\text { *mm } \text { eşdeğer Al kalınlığı. } \\
\text { Tundan }\end{array}$ & $\begin{array}{l}\text { One way } \\
\text { Tukey }\end{array}$ & One way + Tukey \\
\hline Farklı harfler: Gruplar arasındaki anlamlı farklıı̆ı gösterir. \\
\hline
\end{tabular}

\section{TARTIŞMA}

Bu çalışmada operatörün (ve hastanın) radyasyona maruz kalmasını azaltmak, film banyosundaki kimyasalları ortadan kaldırmak, daha yüksek çözünürlük ve $X$ ışını filminden daha büyük dinamik aralık ve görüntü analizini kolaylaştırmak için dijital radyografik sistem kullanımıştır. Aynı zamanda dijital sistem tutarı radyografi gelişimi sağlar. ${ }^{14,15}$

Restoratif materyaller için uygun bir radyoopakIık önemli bir gereksinimdir. Çünkü ışı̆̆ı geçirme ve yansıtma derecesi gibi renk kalitesi göstergeleri radyoopasiteye göre düzenlenir. ${ }^{16}$ Radyoopaklık, mine / dentin ve restoratif materyal arasındaki tekrarlayan diş çürüğü tanısını, hatalı proksimal kontürleri ve uygunsuz marjinal kenarları teşhis etmeyi kolaylaştırır. 8, 17 Restorasyonları değiştirmenin ana sebeplerinden biri tekrarlayan diş çürüğüdür. ${ }^{18}$ Bu nedenle, restorasyon materyalleri, diş - restorasyon ara yüzünün diş yapısından ayırt edilmesini kolaylaştıran en iyi radyoopasiteye sahip olmalıdır. ${ }^{7}$ Salzedas ve ark. ${ }^{19}$ materyallerin radyoopasite bilgisinin diş hekimlerinin tedavi sırasında doğru restoratif materyali seçmelerine yardımcı olabileceğini belirtmişlerdir. Düşük radyoopasiteli materyallerin hatalı teşhise yol açabileceği, çok fazla radyoopasitenin de hem materyalin hem de restorasyon altındaki çürük ve defektin radyografide izlenmesine engel olacağını, bu nedenle orta derecede bir radyoopasitenin radyografın değerlendirilmesinde tercih edildiğini belirtmişlerdir. $8,11,20$

ISO dental materyallerin sahip olması gereken radyoopasite standartlarını tanımlamıştır. ISO 4049'a göre, koronal diş dokusuna uygulanan restoratif materyaller, aynı saf alüminyum kalınlığına benzer veya daha yüksek radyoopasiteye sahip olmalıdır. Ayrıca, ISO 4049'da, restoratif malzemelerin en düşük radyoopasite değerinin, aynı kalınlıktaki dentin ile benzer radyoopasite değerine sahip olması gerektiğini bildirmiştir. ${ }^{21}$ Bu çalışmada, kullanılan tüm malzemeler dentinin radyoopasite değerinden daha fazla radyoopasite göstermiş, böylece ISO standartlarına uygunluk göstermiştir.

Rezin kompozitlerin istenen radyoopasitesi hala tartışmalı bir konudur. Bazı yazarlar, posterior kompozit rezinlerde restorasyon ve diş ayrımının tespiti için rezin kompozitlerin diş yapısından daha yüksek radyoopasiteye sahip olması gerektiğini savunurken ${ }^{6,7,22}$, bir grup yazar ise radyoopasitenin detayların tespitini ve görme keskinliğini bozduğunu ileri sürerler ${ }^{8,}{ }^{23}$ Akıcı rezin kompozitlerinin radyoopasitesinin önemi derin çürük lezyonlarında daha da artmışır. Orta derecede radyoopasiteye sahip restoratif materyaller yüksek derecede radyoopasiteye sahip materyallere göre daha çok tercih edilmektedir. ${ }^{8}$ Bu çalışmada kullanılan materyaller arasında sadece NHF mineden yüksek radyoopasite değeri göstermiştir. Ayrıca BEG ise mineye benzer radyoopasite değeri göstermiştir.

$A F, D F$, GUF dentine benzer, NHF ile BEG ise mineye benzer bir radyoopaklığa sahip olduğu bulunmuştur. Çalışmamızda mine ve dentinin radyoopasite değerleri sırasıyla $2,57 \pm 0,17$ ve $1,34 \pm 0,14 \mathrm{~mm} \mathrm{Al}$ olarak ölçülmüştür, bu değerler daha önce yapılan çalışmalarla uyum içindedir (dentin için bu değer $1 \mathrm{~mm}$ Al 'e ve mine için ise $2,0 \mathrm{~mm}$ Al'e yakındır). ${ }^{24-26} \mathrm{AF}$ ve DF dentine benzer radyoopasite değeri göstermiştir. DF ve GUF' da da dentine benzer değerler elde edilmiştir. BEG ve NHF ise mineye benzer ancak birbirlerinden farklı radyoopasite değeri göstermiştir.

Rezin kompozitlerin radyopaklı̆ı doldurucunun tipine ve yüzdesine bağlıdır. ${ }^{27-29}$ Silikon (silikon dioksit), kuartz, lityum-alüminyum gibi düşük atom numarasına sahip dolduruculardan oluşan materyaller radyolüsent görünürler. Oysaki zirkonyum ( $\mathrm{Zr}$, atom no:40), baryum (Ba, atom no: 56$)$, çinko ( $\mathrm{Zn}$, atom no:30), alüminyum (Al, atom no:13), stronsiyum ( $\mathrm{Sr}$, atom no:38), yitrium ( $Y$,atom no:39), terbiyumtriflorid ve lantan (La, atom no: 57), gibi yüksek atom numarasına sahip doldurucu içeren materyaller $X$ ışınını absorbe etme kapasitesini arttırdıklarından dolayı radyoopak görünürler. ${ }^{28,30,31}$ Yaptı̆ı̆ımı çalışmada, GUF en düşük radyoopasite değerini göstermiştir. Stronsiyum oranı (\%55-70) yüksek olmasına rağmen içerdiği silika (silikon dioksit) nedeniyle dentine benzer bir radyoopaklık gösterdiğini düşünmekteyiz. Bizim sonuçlarımızın aksine; Yıldırım ve ark. ${ }^{32}$ yaptıkları çalışmada GUF' nin MGV'sini, kullandıkları diğer materyallere [(Filtek Ultimate Flowable, Estelite Flow Quick, 
Leaddent Flow, Supraflow, Flowline, Bright light flow)] ve mineye göre daha yüksek olarak bulmuşlardır. GUF'nin farklı MGV göstermesi, çalışmalarda hazırlanan örneklerin boyutlarının ve radyografik prosedürün uygulama farklııklarından kaynaklanmış olabilir.

Attar ve ark.'nın²7 7 akıcı kompozit rezini [(Aelite Flo, Filtek Flow, Heliomolar Flow, PermaFlo, Revolution Formula 2, Tetric Flow, Wave)] ve 2 akıc kompomeri [(Compoglass Flow, Dyract Flow)] radyoopaklık yönünden kıyasladığı çalışmada Tetric Flow en yüksek radyoopasite değerini göstermiştir. AF ise aynı çalışmada bizim çalışmamızda bulunan sonuçlara $(1,64 \pm 0,24)$ benzer radyoopasite değeri (1,80 mm Al) göstermiştir. Ergücü ve ark. 'nın ${ }^{33} ; 6$ tane akıc kompozit rezininin radyoopasitelerini kıyasladıkları çalışmada Tetric N Flow ve Clearfil Majesty Flow 'un radyoopasitelerini mineden daha radyoopak bulmuşlardır. Bizim çalışmamızda BEG, NHF mineye benzer ve daha yüksek radyoopasite değerleri göstermiştir. Bu akıcı kompozit rezinlerin; NHF ve Clearfil Majesty Flow içeriklerindeki silanlı baryum cam, Tetric $\mathrm{N}$ Flow ve NHF akıc kompozit rezinlerin ise içeriklerindeki itterbiyum triflorür doldurucuları benzerdir. İçeriklerindeki bu dolduruculardan dolayı radyoopasiteleri mineye eşdeğer ya da yüksek bulunduğunu düşünmekteyiz. Ergücü ve ark. ${ }^{33}$; akıcı kompozit rezinlerin radyoopasiteleri de düşünüldüğünde, radyoopasitesi mineye göre yüksek akıcı kompozit rezinlerin posterior restorasyonlar için daha uygun olduğunu yaptıkları çalışmada belirtmişlerdir.

\section{SONUÇ}

Piyasaya sürülen akıcı kompozit rezinlerin radyoopasiteleri ve içerdikleri doldurucuların çeşidi oldukça değişkendir. Bu çalışmada kullanılan tüm akıcı kompozit rezinler ISO standartlarını karşılamıştır. Kompozit rezin restorasyonların altında sekonder çürüklerle karıştırılmaması için yüksek radyoopasite değerlerine sahip akıc kompozit rezinler kullanılabilir. Radyografik analiz yaparken bu farklı radyoopasite değerlerini bilmek tanıya yardımcı olacaktır. Akıcı kompozit rezinlerin radyoopasitesiyle ilgili oldukça sınırlı çalışma bulunmaktadır. Bu nedenle bu kompozit rezinlerle ilgili daha ileri çalışmalara gereksinim duyulmaktadır.

NOT: Calışmada herhangi bir yazar, kurum ya da kuruluş ile çıkar çatışması içerisinde bulunmamaktadır. Makale daha önce hiçbir yerde yayınlanmamış ve yayınlanmak üzere işlem görmemektedir

\section{KAYNAKLAR}

1. Jackson RD, Morgan M. The new posterior resins and: a simplified placement technique. J. Am. Dent. Assoc 2000; 131: 375-83.

2. Stephen $\mathrm{CB}$. A characterization of first-generation flowable composites. JADA, 1998; 129: 567-77.

3. Summitt JB, Robbins JW, Hilton TJ, Schwartz RS, Dos Santos Jr J Fundamentals of operative dentistry: a contemporary approach. Baskı. Quintessence Pub 2006.

4. Cadenaro M, Marchesi G, Antoniolli F, Davidson C, Dorigo EDS, Breschi L. Flowability of composites is no guarantee for contraction stress reduction. Dent Mater J 2009, 25: 649-54.

5. Lee I-B, Min S-H, Kim S-Y, Ferracane J Slumping tendency and rheological properties of flowable composites. Dent Mater J, 2010, 26: 443-448.

6. Imperiano MT, Khoury HJ, Pontual MLA, Montes MAJR, Silveira MMF. Comparative radiopacity of four lowviscosity composites. Braz J Oral Sci 2007; 6: 1278-82.

7. Bouschlicher M, Cobb D, Boyer D. Radiopacity of compomers, flowable and conventional resin composites for posterior restorations. Oper. Dent 1999; 24: 20-5.

8. Espelid I, Tveit AB, Erickson RL, Keck SC, Glasspoole EA. Radiopacity of restorations and detection of secondary caries. Dent Mater J 1991; 7: 114-7.

9. Koliniotou-Koumpia $E$, Dionysopoulos $P$, Papadimitriou S, Koumbia E, Dionysopoulos D. Sealing effectiveness of two liners and one flowable composite resin in vivo in class $\mathrm{V}$ restorations. Hellenic Dent. ] 2006; 16: 11-6.

10. Marouf N, Sidhu S. A study on the radiopacity of different shades of resin-modified glass-ionomer restorative materials. Oper. Dent 1998; 23: 10-4.

11. Hara AT, Serra MC, AL RJ Radiopacity of glassionomer/composite resin hybrid materials. Braz Dent J 2001; 12:85-9.

12. Chan D, Titus $H$, Chung $K-H$, Dixon $H$, Wellinghoff S, Rawls $\mathrm{H}$. Radiopacity of tantalum oxide nanoparticle filled resins. Dent Mater J 1999; 15: 219-22.

13. Van Dijken JW, Wing KR, Ruyter IE. An evaluation of the radiopacity of composite restorative materials used in Class I and Class II cavities. Acta Odontol. Scand 1989; 47: 401-7. 
14. Nomoto R, Mishima A, Kobayashi K, McCabe J, Darvell B, Watts D, Momoi Y, Hirano S. Quantitative determination of radio-opacity: equivalence of digital and film X-ray systems. Dent Mater J 2008; 24: 141-7.

15. Camps J, Pommel L, Bukiet F. Evaluation of periapical lesion healing by correction of gray values. J Endod 2004; , 30: 762-6.

16. Santos MC AC, Khoury H, Braz R. Evaluation of radiopacities two compomers. Rev Odontol Univ Santo Amaro 1999; 40: 5

17. Aguiar CM AK, Santos MC, Becerra SR. Diagnosis of caries dental. Rev Odontol Univ Santo Amaro 1998; 3: 31.

18. Braga SR, Vasconcelos $B T$, Macedo MR, Martins VR, Sobral MA. Reasons for placement and replacement of direct restorative materials in Brazil. Quintessence Int 2007; 38: e189-94.

19. Salzedas LM LM, de Oliveira Filho AB. Radiopacity of restorative materials using digital images. J Appl Oral Sci 2006; 14: 52.

20. Kuter B, Ece E. Restoratif cam iyonomer simanlarin radyoopasitelerinin iki farkli teknikle karşilaştirilmasi. Atatürk Üniv Diş Hek Fak Derg 2010; 20: 1-6

21. Motohashi J, Furukawa S, Shimoda S, TSURUMOTO A. ISO 4049 Dentistry-polymerbased filling, restorative and luting materials ISO 4049 Dentistry-polymer-based filling, restorative and luting materials, 1-22, 2000. J Hard Tissue Biol 2010; 19: 195-202.

22. Murchison DF, Charlton DG, Moore WS. Comparative radiopacity of flowable resin composites. Quintessence Int 1999; 30:1.

23. Watts D, McCabe J Aluminium radiopacity standards for dentistry: an international survey. J Dent 1999; 27: 73-8.

24. Williams J, Billington R. The radiopacity of glass ionomer dental materials. J Oral Rehabil 1990; 17: $245-8$

25. El-Mowafy O, Brown J, McComb D. Radiopacity of direct ceramic inlay restoratives. J Dent 1991; 19: $366-8$

26. Dukic W, Delija B, Derossi D, Dadic I. Radiopacity of composite dental materials using a digital X-ray system. Dent Mater J, 2012: 47-53

27. Attar N, Tam LE, McComb D. Flow, strength, stiffness and radiopacity of flowable resin composites. J Can Dent Assoc 2003; 69: 516-21.
28. Sabbagh J, Vreven J, Leloup G. Radiopacity of resin-based materials measured in film radiographs and storage phosphor plate (Digora). Oper Dent 2004; 29: 677-84.

29. Nakamura $\mathrm{T}$, Tanaka $\mathrm{H}$, Kawamura $\mathrm{Y}$, Wakabayashi K. Translucency of glass-fibrereinforced composite materials. J Oral Rehabil 2004; 31: 817-21.

30. Jandt KD, Al-Jasser AM, Al-Ateeq K, Vowles RW, Allen GC. Mechanical properties and radiopacity of experimental glass-silica-metal hybrid composites. Dent Mater J 2002; 18: 429-35.

31. Tsuge T. Radiopacity of conventional, resinmodified glass ionomer, and resin-based luting materials. J Oral Sci 2009; 51: 223-30.

32. Yildirim D, Ermis RB, Gormez O, Yildiz G. Comparison of radiopacities of different flowable resin composites. JOMR 2014; 2: 21.

33. Ergücü $Z$, Türkün $L$, Önem $E$, Güneri $P$. Comparative radiopacity of six flowable resin composites. Oper. Dent 2010; 35: 436-40.

\section{Yazışma Adresi}

Dr. Kübra CANTÜRK

Atatürk Üniversitesi, Diş Hekimliği Fakültesi, Diş Hast. Ve Ted. AD, Erzurum

Telefon: +9005065728757

e-mail: dt.kubrakulakoglu@gmail.com 